OPEN ACCESS

Edited by:

Francesco Baino,

Politecnico di Torino, Italy

Reviewed by:

Masoud Mozafari,

University of Toronto, Canada

Sergey V. Dorozhkin,

Independent Researcher, Russia

*Correspondence:

Cyril d'Arros

cyrildarros@biomatlante.com

Specialty section: This article was submitted to Biomaterials,

a section of the journal Frontiers in Bioengineering and

Biotechnology

Received: 08 November 2019 Accepted: 19 December 2019 Published: 28 January 2020

Citation:

d'Arros $C$, Rouillon T, Veziers J,

Malard $O$, Borget $P$ and Daculsi G (2020) Bioactivity of Biphasic Calcium Phosphate Granules, the Control of a Needle-Like Apatite Layer Formation for Further Medical Device Developments

Front. Bioeng. Biotechnol. 7:462 doi: 10.3389/fbioe.2019.00462

\section{Bioactivity of Biphasic Calcium Phosphate Granules, the Control of a Needle-Like Apatite Layer Formation for Further Medical Device Developments}

\author{
Cyril d'Arros ${ }^{1,2 *}$, Thierry Rouillon ${ }^{1,3}$, Joelle Veziers ${ }^{1,3,4,5}$, Olivier Malard ${ }^{1,6}$, Pascal Borget ${ }^{2}$ \\ and Guy Daculsi'
}

${ }^{1}$ INSERM, UMR 1229, Regenerative Medicine and Skeleton, ONIRIS, Université de Nantes, Nantes, France, ${ }^{2}$ BiomatlanteAdvanced Medical Solutions Group plc, Vigneux-de-Bretagne, France, ${ }^{3}$ UFR Odontologie, Université de Nantes, Nantes, France, ${ }^{4}$ PHU4 OTONN, CHU de Nantes, Nantes, France, ${ }^{5}$ INSERM, UMS 016, CNRS 3556, Structure Fédérative de Recherche François Bonamy, SC3M Facility, CHU de Nantes, Université de Nantes, Nantes, France, ${ }^{6}$ Service d'Oto-Rhino-Laryngologie et de Chirurgie Cervico-Faciale, PHU4 OTONN, CHU de Nantes, Nantes, France

Biphasic calcium phosphate (BCP) bioceramics (hydroxyapatite/tricalcium phosphate, or HATTCP) for tissue engineering and drug delivery systems is a unique know-how. A mechanical mixture of HA and TCP does not lead to such bioactive ceramics. The wet elaboration conditions of calcium-deficient apatite (CDA) or CDHA, followed by sintering, converts it into TCP and HA. The dissolution precipitation of nanosized needle-like crystals at the surface of BCP occurs on time at body temperature. Combining several technics of characterization [scanning electron microscopy (SEM), transmission electron microscopy (TEM), energy-dispersive $x$-ray spectroscopy (EDX), Brunauer-Emmett-Teller method (BET), chemical analysis, $x$-ray diffraction (XRD), Fourier transformed infrared spectroscopy (FTIR)], we demonstrated an evolution on time of the HA $\beta$-TCP. The current paper describes the crystallographic evolution of initial $\beta$-TCP rhombohedral crystallographic structure to microsized needle-like layer corresponding to apatitic TCP form. This phenomenon leads to an increase of the HA/TCP ratio, since hexagonal apatitic TCP is similar to hexagonal HA. However, the $\mathrm{Ca} / \mathrm{P}$ ratio (reflecting the chemical composition HA/TCP) remains unchanged. Thus, the high reactivity of BCP involves dynamic evolution from rhombohedral to hexagonal structure, but not a chemical change. The dynamic process is reversible by calcination. These events are absolutely necessary for smart scaffolds in bone regeneration and orthobiology.

Keywords: biphasic calcium phosphate, bioactive ceramic, apatitic needle-like layer, bioactivity, apatitic TCP

\section{INTRODUCTION}

Many clinical situations require materials to restore and regenerate the bone. In spite of large innovations during the last 30 years (Wagner et al., 2018), the optimization of synthetic bone substitutes is still required to have an efficient clinical alternative to the gold standard, the autograft, which has several limitations frequently described in the literature (Heary et al., 2002; 
Silber et al., 2003). An important part of synthetic bone graft development in the last few decades concerns calcium phosphate $(\mathrm{CaP})$ bioceramics as a replacement for auto- and allografts (Giannoudis et al., 2005; Dorozhkin, 2010; Habraken et al., 2016), or xenografts (Daculsi et al., 2006). This can be achieved by the in vivo formation of a carbonated apatite layer allowing for a strong interaction of the implanted $\mathrm{CaP}$ materials with the host bone as demonstrated 30 years ago (Daculsi et al., 1990). The recent evaluation (Bohner and Miron, 2019) of the apatitic precipitation clearly confirms that this process is a prerequisite for a bioactive $\mathrm{CaP}$ bioactive materials. To predict the bonding of synthetic materials to a living bone, an in vitro method was assessed based on the observation of apatite layer onto the surface of synthetic materials immerged in a simulated body fluid, with ion concentrations nearly equal to those of human blood plasma (Kokubo and Takadama, 2006). This property was further defined as bioactivity.

Biphasic calcium phosphates (BCP) are largely used in clinical situations. The ratio of hydroxyapatite (HA) and $\beta$-tricalcium phosphate $(\beta$-TCP) is a crucial parameter concerning the bioactivity of this kind of bone substitute, due to different solubilities between both compounds of BCP (Lin et al., 2003; Dorozhkin, 2010). Lower sintering temperature $\left(<1200^{\circ} \mathrm{C}\right)$ respects the chemical composition and the high reactivity of the bioceramics in terms of dissolution/precipitation required for effective bone regeneration technologies (Gauthier et al., 1999; Habibovic et al., 2006a). In addition, the macro- and microporosity of $\mathrm{CaP}$ bioceramics play a fundamental and key role in the osteoinduction process (Daculsi and Layrolle, 2004; LeGeros, 2008; Champion, 2013; Eliaz and Metoki, 2017).

$\mathrm{MBCP}^{\circledR}+\mathrm{BCP}$ synthetic bone graft is currently used in clinical trials as a scaffold for tissue engineering strategy. Indeed in vitro and in vivo experiments testing autologous mesenchymal stem cells associated with these BCP granules displayed excellent results in bone regeneration (Cordonnier et al., 2010; Brennan et al., 2014). A clinical trial's results demonstrated a promising future for the use of autologous stem cells combined with highly bioactive BCP granules (Gjerde et al., 2018; Gómez-Barrena et al., 2019).

New scaffolds designs have to be more suitable for a tissue engineering approach, improving usability for surgeons at the same time. It appears that ease of use and handling of injectable or moldable paste bone medical devices are much anticipated (Bohner, 2010). One of the most important goals for new synthetic bone substitute development is to facilitate its handling for the surgeons while at the same time maintaining the bioactivity of highly reactive $\mathrm{CaP}$ bioceramics. Using hydrophilic carriers with $\mathrm{CaP}$ granules for pastes and putties can lead to interaction with mineral phase over time (Bourges et al., 2001; Schmitt et al., 2002; Davison et al., 2012).

It is therefore of prime importance to understand how it is possible to get a bioactive layer on BCP materials and what the physicochemical composition of this layer is to better control its formation, in order to develop the next generation of synthetic bone graft materials.

\section{MATERIALS AND METHODS}

\section{BCP Samples}

\section{Washing, Drying, and Sintering}

The $\mathrm{MBCP}^{\circledR}+$ bioceramic (Biomatlante SA, France) was used in this study. This commercial BCP is an intimate mixture at the molecular level of $20 \%$ of HA and $80 \%$ of $\beta$-TCP sterilized by beta irradiation (25 kGy).

Three batches of $\mathrm{MBCP}^{\circledR}+$ granules were considered and labeled BCP1, BCP2, and BCP3, corresponding to batch numbers 0716J116, 0916J216, and 1016J216, respectively. Five hundred micrograms of each batch was washed separately three times for $5 \mathrm{~min}$ ultrasonically in distilled water, then dried in an oven at $200^{\circ} \mathrm{C}$ for $4 \mathrm{~h}$ and labeled _W\&D (for washed and dried). Ten grams of each batch was then sintered again at low temperature following Biomatlante SA's validated process $\left(<1100^{\circ} \mathrm{C}\right)$ and _W\&D_S (for washed, dried, and sintered). Denominations of all the samples used in the study are summarized in Supplementary Data $\$$.

Granules (1-2 mm) were analyzed using scanning electron microscopy (SEM), x-ray diffraction (XRD), atomic absorption spectrometry (AAS) for the $\mathrm{Ca} / \mathrm{P}$ ratio, and Fourier transformed infrared spectroscopy (FTIR) analyses. The Brunauer-EmmettTeller (BET) method for specific surface area (SSA) analyses was performed on 0.5 to $1 \mathrm{~mm}$ granules of BCP2.

\section{Effect of Higher Sintering Temperature}

To investigate the effect of higher sintering temperature on the bioactivity, two samples ( $1 \mathrm{~g}$ of 0.5 to $1 \mathrm{~mm}$ granules each) were examined: one control (BCP_0) and another one (BCP_1200) whose microstructure was modified by an additional sintering step at higher temperature $\left(1200^{\circ} \mathrm{C} / 5 \mathrm{~h}\right)$.

Each batch was washed and dried as previously described (labeled_W\&D) with more efficiency due to the small amount considered ( $1 \mathrm{~g}$ instead of $500 \mathrm{~g}$ ). Both samples were then stored in wet conditions at $37^{\circ} \mathrm{C}$ for 2 months and freeze-dried to remove residual water instead of conventional drying in the oven (labeled _W\&37/2M). Denominations of all the samples used in the study are summarized in Supplementary Data S1.

\section{Characterization}

\section{Scanning Electron Microscopy}

Biphasic calcium phosphate granules were coated with gold using a Desk V Sputter (Denton Vacuum), and the surface topographies were examined by secondary electrons using a SEM (LEO 1450VP) at an acceleration voltage of $10 \mathrm{keV}$ and $30 \mathrm{~mA}$.

\section{Specific Surface Area}

The SSA was determined by the BET method. The BET experiment was measured by nitrogen gas adsorption on a Micromeritics 3-FLEX equipment. Samples were weighed (about $100 \mathrm{mg})$ and degassed in vacuum conditions $\left(10^{-3} \mathrm{mbar}\right)$ at $150^{\circ} \mathrm{C}$ for $24 \mathrm{~h}$. Following this step, the samples were precisely weighed and their SSAs were calculated from the range of relative pressure of adsorption-desorption isotherms by $0.05-0.2$. The unit of BET SSA is $\mathrm{m}^{2} / \mathrm{g}$. 


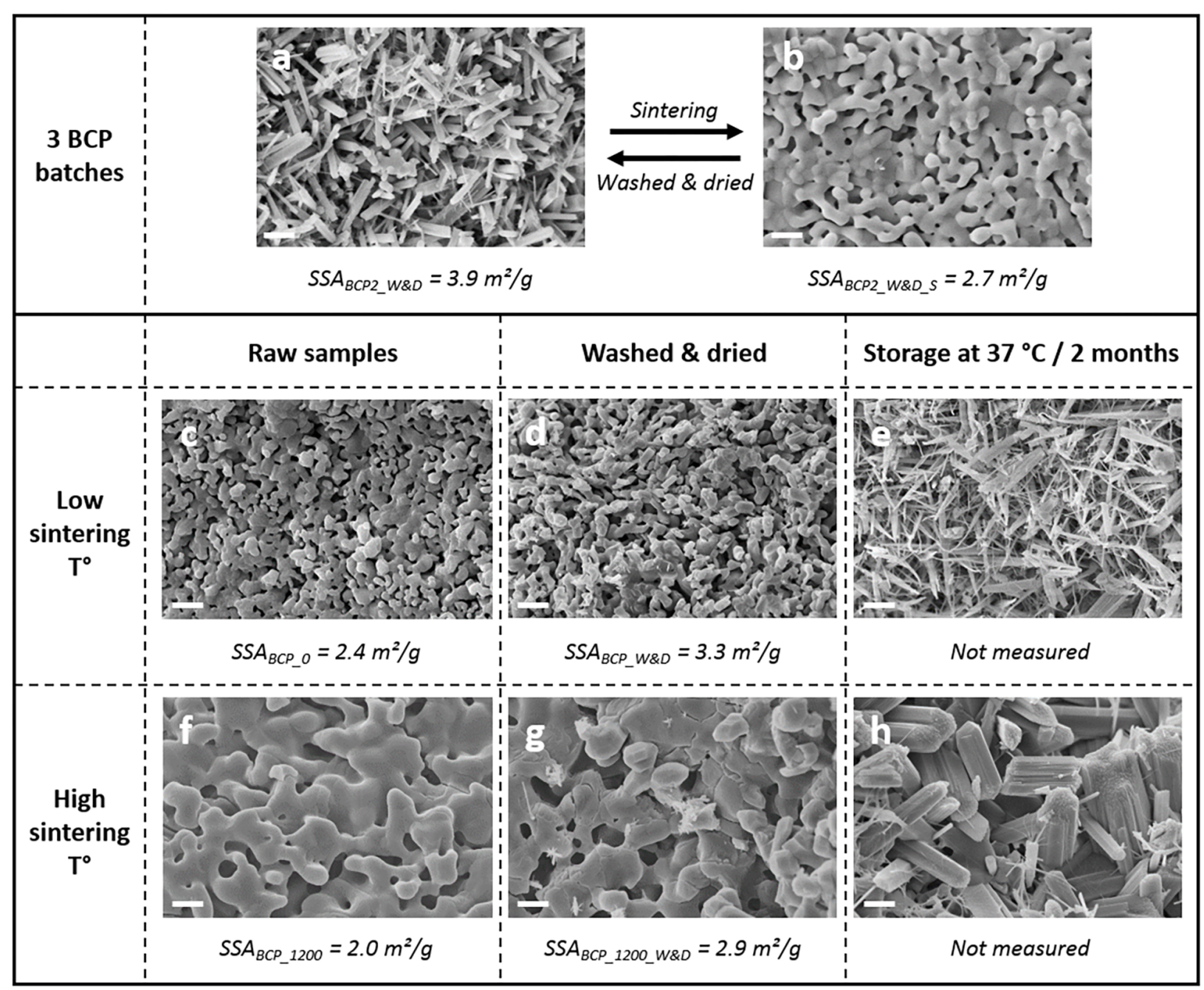

FIGURE 1 | Scanning electron microscopy (SEM) observations (magnification $\times 5000$, scale bar of $2 \mu \mathrm{m}$ ) on the effect of the washing and drying on biphasic calcium phosphate (BCP) granules (a) and BCP surface after a new low-temperature sintering step (b). Comparison of the original BCP granules in different conditions (c, sample BCP_0) and the same granules after a new sintering step at $1200^{\circ} \mathrm{C} / 5 \mathrm{~h}$ (f, sample BCP_1200), with the evolution of surface after washing and drying for a small amount (d, g, respectively; BCP W\&D and BCP 1200 W\&D for original and $1200^{\circ} \mathrm{C}$ sintered BCP), and after washing and storage at $37^{\circ} \mathrm{C}$ for 2 months before freeze drying (e,h, respectively; for BCP_W\&37/2M and BCP_1200_W\&37/2M)., using the Brunauer-Emmett-Teller (BET) method to determine the specific surface area values of washed and dried granules and sintered at low and high sintering temperatures of $\mathrm{MBCP}{ }^{\circledR}+$ granules $(\mathbf{a}-\mathbf{d}, \mathbf{f}, \mathbf{g})$.

\section{X-Ray Diffraction}

The identification phase of BCP materials was determined by analyzing the x-ray powder diffraction (XRD) data recorded using a Philips PW 1830 generator equipped with a copper $\mathrm{X}$-ray tube, a vertical PW $1050(\theta / 2 \theta)$ goniometer, and a PW 1711 Xe detector. Measurements were performed using the $\mathrm{CuKa}$ radiation ( $\mathrm{Ni}$ filtered) and recorded in a stepby-step mode of $2 \theta$ from $3^{\circ}$ to $70^{\circ}$ with a step $2 \theta$ of $0.03^{\circ}$ and a counting time per step of $3 \mathrm{~s}$. The HA/ $\beta$-TCP ratio (or hexagonal/rhombohedral phases ratio) of the $\mathrm{BCP}$ powder (without and with an apatitic surface layer formation, respectively) was determined from XRD measurements based on the ratio of peak height of the most intense reflection of each phase, corresponding to the $\left(\begin{array}{lll}0 & 2 & 10\end{array}\right)$ reflection at $2 \theta \approx 31.0^{\circ}$ for the rhombohedral phase ( $\beta$-TCP, ICDD-PDF database ref. 009-0169) and to the (2 111$)$ reflection at $2 \theta$ $\approx 31.7^{\circ}$ for the hexagonal phase (HA, ICDD-PDF database ref. 009-0432).

\section{CaP Analyses}

The dosages of calcium and phosphates allowed for determining the $\mathrm{Ca} / \mathrm{P}$ ratio are particularly important concerning the characterization of a BCP.

Calcium analysis was performed by AAS using a Thermo Scientific ICE 3300 spectrometer. Around $250 \mathrm{mg}$ of BCP powder was dissolved in around $15 \mathrm{ml}$ of concentrated nitric acid- $\mathrm{HNO}_{3}$ $(65 \%)$ and then diluted with deionized water and completed with lanthanum chloride in order to obtain a final solution of around $2 \mathrm{mg} / \mathrm{L}$ of calcium with $1 \% \mathrm{HNO}_{3}$ and $1 \%$ lanthanum (in order to avoid interference phenomena in the flame). Measurements 


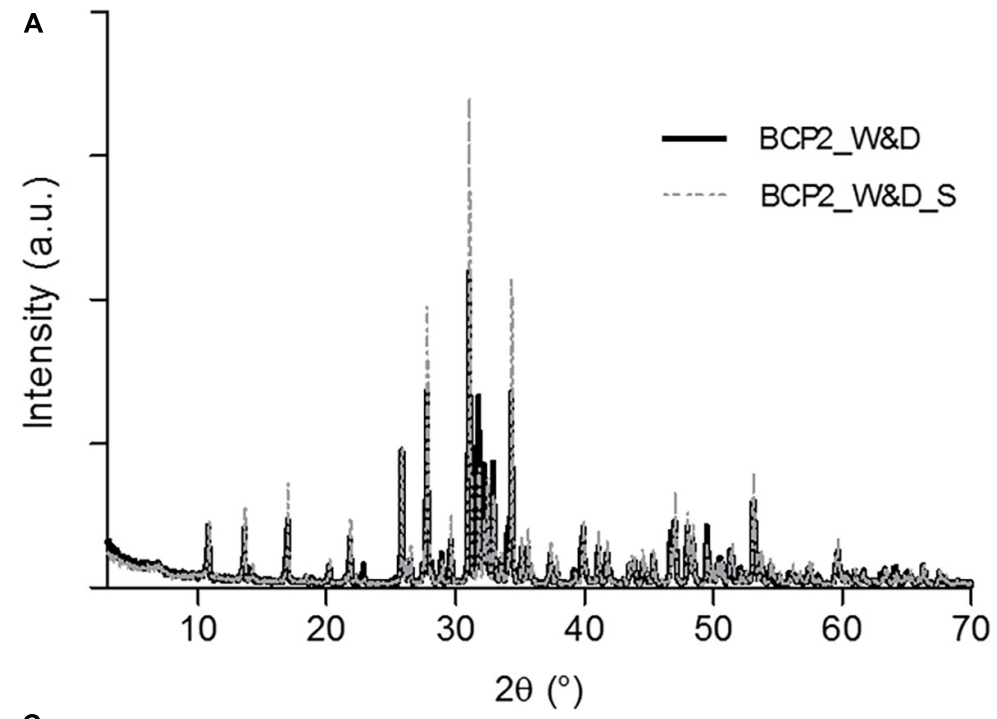

C

\begin{tabular}{c|cc|cc|cc}
\hline & \multicolumn{2}{|c|}{ BCP1 } & \multicolumn{2}{c|}{ BCP2 } & \multicolumn{2}{c}{ BCP3 } \\
\hline & W\&D & S & W\&D & S & W\&D & S \\
Phase a & 39 & 22 & 37 & 19 & 43 & 22 \\
Phase b & 61 & 78 & 63 & 81 & 57 & 78 \\
\hline
\end{tabular}

Phase a: Cristaline structure apatitic like (hexagonal) Phase b: Cristaline structure $\beta$-TCP like (rhombohedral)
B

Phase $b$

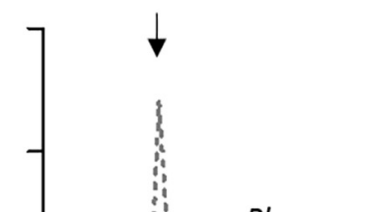

Phase a

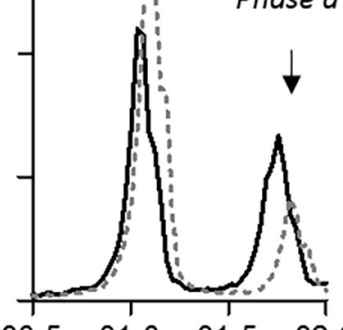

$\begin{array}{llll}30.5 & 31.0 & 31.5 & 32.0\end{array}$

$2 \theta\left(^{\circ}\right)$

D

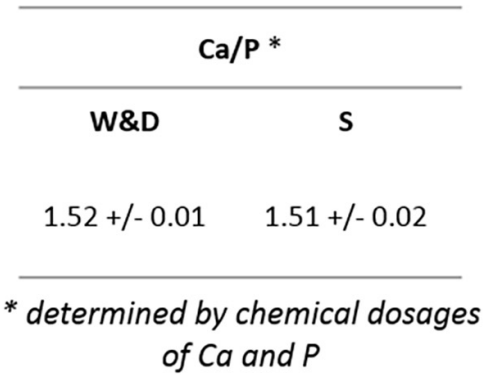

FIGURE 2 |X-ray diffraction (XRD) analyses and calcium phosphate dosages of BCP granules in both conditions. (A) Representative graph of XRD analysis after washing and drying, BCP2_W\&D, and after a new sintering step, BCP2_W\&D_S). (B) Focused graph on both peaks for quantification of phases a and b. Table summarizing $(\mathbf{C})$ the results of the quantification of both phases a and $b$ for three batches, and (D) the results of the Ca/P ratio determined by chemical dosages of three batches (BCP1, BCP2, and BCP3).

of absorbance were performed at $422.7 \mathrm{~nm}$ using a calcium lamp and an air/acetylene flame. Calibration was performed from solutions of different concentrations of calcium with $1 \% \mathrm{HNO}_{3}$ and $1 \%$ lanthanum, and prepared from a $1 \mathrm{~g} / \mathrm{L}$ of certified calcium solution (ref. 86667.260 VWR).

The phosphate ions $\left(\mathrm{PO}_{4}{ }^{3-}\right)$ concentration was determined by colorimetry using a PerkinElmer Lambda25 UV/Vis spectrometer. Vanadate-molybdate reagent (ref. 1.08498.0500; Merck) was used to determine the phosphate concentration. Around $100 \mathrm{mg}$ of BCP powder was dissolved in $5 \mathrm{ml}$ of concentrated nitric acid- $\mathrm{HNO}_{3}(65 \%)$ and then diluted with deionized water and adjusted with Titripur ${ }^{\circledR}$ Sodium Hydroxide solution $1 \mathrm{~N}$ (ref. 1.09137.1000; Merck) or Titripur ${ }^{\circledR}$ Sulfuric Acid $1 \mathrm{~N}$ (ref. 1.09072.1000; Merck) in order to obtain a neutral solution ( $\mathrm{pH}$ around 7 ) with an amount of phosphates corresponding to approximatively $100 \mathrm{mg} / \mathrm{L}$ of BCP sample. Measurements of absorbance were performed at $405 \mathrm{~nm}, 15 \mathrm{~min}$ after adding and agitating $5 \mathrm{ml}$ of the sample solution with $1 \mathrm{ml}$ of the V-M reagent. Calibration was performed from solutions of different concentrations of phosphate, prepared by dilutions from $1 \mathrm{~g} / \mathrm{L}$ of phosphate solution (potassium dihydrogen phosphate anhydrous, ref. 1.05108.050; Merck).

\section{Fourier Transformed Infrared Spectroscopy}

Pellets made of around 1-2 mg of crushed samples, mixed with $300 \mathrm{mg}$ of $\mathrm{KBr}$ and pressed, were prepared, and infrared absorption spectra by transmission were collected in the 400to $4000-\mathrm{cm}^{-1}$ spectral range with a resolution of $4 \mathrm{~cm}^{-1}$ and an accumulation of 64 scans using a Nicolet Magnat II 550 FTIR spectrometer.

\section{Transmission Electron Microscopy}

A small amount of BCP sample was shaken vigorously in less than $1 \mathrm{ml}$ of pure-grade ethanol, after which the larger particles descended to the bottom. A few drops of the supernatant with needle suspension were deposited on a nickel grid for transmission electron microscopy (TEM) and covered with holey carbon film. After solvent evaporation, the grid was observed by TEM using a 1010 JEOL electron microscope operating at an accelerating voltage of $100 \mathrm{kV}$. Selected area electron diffraction (SAED) patterns were performed at $100 \mathrm{kV}$, with a doubletilt holder, and the diffraction constant was calibrated using an evaporated aluminum film as a standard. Energy-dispersive $\mathrm{x}$-ray spectroscopy (EDX) measurements were performed at $100 \mathrm{kV}$ using an Oxford Instruments Link ISIS spectrometer, 
equipped with an ATW2 ultrathin window (energy resolution: $142 \mathrm{eV}$ at $5.9 \mathrm{keV}$ ).

The mean value of the $\mathrm{Ca} / \mathrm{P}$ atomic ratio of needles was determined from EDX microanalyses performed on more than 10 different needles. Quantitative analyses were obtained on the basis of thin film approximation, and the calcium and phosphorus experimental Cliff-Lorimer $\mathrm{K}$ factors were standardized from analyses performed under the same conditions on $\beta$-TCP $\left[\beta-\mathrm{Ca}_{3}\left(\mathrm{PO}_{4}\right)_{2}\right]$ and octa calcium phosphate $\left[\mathrm{Ca}_{8} \mathrm{H}_{2}\left(\mathrm{PO}_{4}\right)_{6} \cdot 5 \mathrm{H}_{2} \mathrm{O}\right]$ standards. Schematic $2 \mathrm{D}$ representations of the reciprocal lattice compared to ED patterns were simulated using CaRIne Crystallography 3.1 software with a hexagonal crystallographic cell corresponding to the $\mathrm{HA}$ crystalline structure $(a=9.42 \AA, c=6.88 \AA$, space group P $63 / \mathrm{m})$.

\section{RESULTS AND DISCUSSION}

Scanning electron microscopy images illustrate the easy capacity of BCP granules to form an apatitic layer on the surface. Indeed a needle-like structure recovers the whole surface of BCP just after being washed in distilled water and dried in an oven. This kind of result is often sought-after and obtained in more critical situations by using an autoclave (De Groot-Barrere et al., 2015; Duan et al., 2019) in order to improve the bioactivity of the BCP biomaterial. Duan et al. (2019) described higher protein adsorptions and an improved in vivo bone regeneration with the presence of needles on the $\mathrm{BCP}$ bone graft compared to standard microporous samples. This study shows that this phenomenon is a reversible one since the initial surface is recovered after a new sintering step (Figures 1a,b) as described in a previous study by Bohne et al. (1993). The reproducibility is confirmed on three batches of the BCP (representative images in Figures 1a,b). A higher sintering temperature leads to the increase of grain size of the bioceramic (Figures $\mathbf{1} \mathbf{c}, \mathbf{f}$ ) as extensively described in the literature (Habibovic et al., 2006b). Washing a small amount of $\mathrm{BCP}$ granules in distilled water and drying at $200^{\circ} \mathrm{C}\left(\mathrm{BCP}_{-} \mathrm{W} \& \mathrm{D}\right.$, Figure 1c) lead to a less important surface modification in comparison to the first condition (BCP1_W\&D, BCP2_W\&D, and BCP3_W\&D illustrated in Figure 1a). This is also observed on the surface of granules sintered at a higher temperature (BCP_1200_W\&D, Figure 1g). The most interesting part of this study concerns the formation of a needle-like surface of BCP granules not only at high temperature during drying but also at $37^{\circ} \mathrm{C}$ near physiological conditions (Figures 1e,h). The size of the newly formed needle-like crystals is proportional to the initial grain size of the BCP (at low and higher sintering temperatures). This high chemical reactivity could explain the important bioactivity of BCP granules and classify it as a smart scaffold (Daculsi, 2015; Zhang et al., 2018). Numerous publications and reviews in the field of bioceramics indicated that the microporosity for bioactive resorbable material is a crucial parameter (Lin et al., 2003; Habibovic et al., 2006a; LeGeros, 2008). This study points out the importance of other parameters to keep a highly reactive BCP (Figure $\mathbf{1 h}$ still shows a modification of surface layer on BCP with a high sintering temperature, which decreases the quantity and size of the microporosity). The synthesis method by wet precipitation of BCP leads to an intimate mixing of HA and $\beta$-TCP phases at a submicronic level (Miramond et al., 2014b), and then improves this high reactivity exposed in the present study. The role of lattice defects in the case of low sintering temperature should also explain the high reactivity of the BCP as demonstrated in 2005 (Daculsi et al., 2005).

The washing and drying steps increase the SSA of about $30 \%$ for the three kinds of materials tested (BCP2 of the $500 \mathrm{~g}$ washed and dried batch, BCP of the $1 \mathrm{~g}$ washed and dried batch, and BCP sintered at high temperature) with about $4 \mathrm{~m}^{2} / \mathrm{g}$ for $0.5-$ $1 \mathrm{~mm} \mathrm{MBCP}{ }^{\circledR}+$ granules. The high sintering temperature of $1200^{\circ} \mathrm{C}$ leads to a decrease of the SSA compared to that of the original BCP granules. The values of this analysis correspond to the ones found in the literature with about $2.5 \mathrm{~m}^{2} / \mathrm{g}$ (Miramond et al., 2014a; Duan et al., 2018). A coherent correlation is possible between SEM observations (Figures 1a-d,f,g) and SSAs. The increase of the SSA values should be more important with smaller granule sizes because of the more important proportion of the surface compared to the mass of the material. In this way, it could be possible to have a control on the BET SSA with the size of the granules and the conditions of washing and drying. A high SSA of granules is a key parameter for the design of drug delivery systems for peptide adsorption and long time delivery as described for spine fusion (Smucker et al., 2008).

The XRD analysis demonstrated different patterns between the washed and dried granules and the granules just after new sintering step. A rapid analysis would lead to a wrong interpretation and a ratio HA/ $\beta$-TCP of about $40 / 60$ for the conditions after washing and drying. However, the analysis after a sintering step $\left(1000^{\circ} \mathrm{C} / 15 \mathrm{~h}\right.$ as required by ISO $13779-3$ standard) (Afnor, 2019) shows the expected 20/80 (HA/ $\beta$-TCP) ratio announced by the manufacturer. These repeated results of the three batches are summarized in Figure 2. The calcium and phosphate dosages confirm that the $\mathrm{Ca} / \mathrm{P}$ ratio is not affected by the washing and drying process for the three batches used in the first part of the study. The increase of the hexagonal phase coupled with the SEM observations can be related to the apatitic surface formation on the surfaces of the granules as described in the literature (Mortier et al., 1989a,b). The observed needle-like structure seems to be exactly the same as that found on the BCP granules of our study. The evident explanation of this observed phenomenon should be the dissolution and precipitation of the BCP leading to a deposited CDA in the needle-like TCP apatitic layer due to a higher solubility of $\beta$-TCP compared to HA as extensively described in the literature (Dorozhkin, 2010). This specific chemical composition of $\mathrm{MBCP}^{\circledR}$ technology granules could explain the high bioactivity and the excellent osteointegration of this biomaterial after in vivo implantation (Daculsi et al., 1990; Rohanizadeh et al., 1999). Moreover, this dynamic evolution on the surface of the BCP granules without any additional ions, contrary to the method proposed by Kokubo and Takadama (2006) for the assessment of the bioactivity of biomaterials with SBF solution, demonstrates the smart response of this $\mathrm{BCP}$ at physiological temperature. The immersion in SBF solution also induces the precipitation of an apatitic layer on the $\mathrm{MBCP}^{\circledR}$ granules and a high protein 


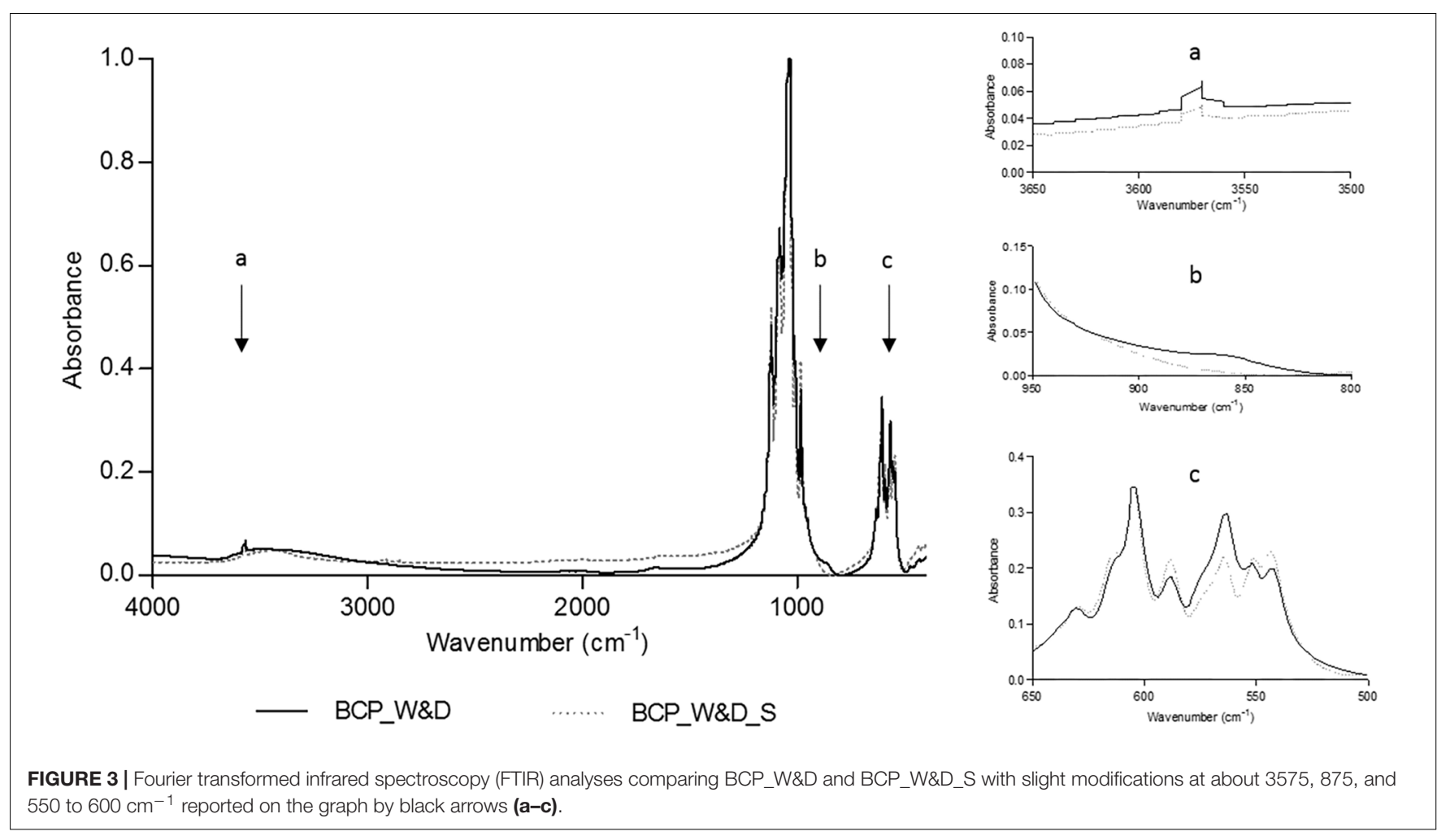

adsorption capacity (Duan et al., 2018). In the ratio 20/80 $(\mathrm{HA} / \beta-\mathrm{TCP})$ of $\mathrm{MBCP}^{\circledR}+$ granules, the high proportion of the most soluble compound ( $\beta$-TCP) in this BCP should improve the important bioactivity of this bioceramic. The presence of $\mathrm{HA}$ in BCP seems to be very important and could play a role of a catalyzer for the crystalline growth of apatitic layer with hexagonal phase structure (Rohanizadeh et al., 1999; De GrootBarrere et al., 2015). This process of dissolution and precipitation has been described in high-resolution TEM (Hr TEM) as a secondary nucleation process and heteroepitaxic crystal growth (Daculsi et al., 1990).

The FTIR analysis comparing conditions after a simple washing and drying (BCP_W\&D) and the same BCP after an additional sintering step (BCP_W\&D_S) shows that the needlelike surface should probably be an apatitic TCP layer. As displayed by equation 1 , the reaction of $\beta$-TCP with water gives apatitic TCP with new easily identifiable groups on the FTIR spectrum.

$$
\begin{array}{cc}
3 \mathrm{Ca}_{3}\left(\mathrm{PO}_{4}\right)_{2}+\mathrm{H}_{2} \mathrm{O} \rightarrow & \mathrm{Ca}_{9}\left[\left(\mathrm{HPO}_{4}\right)\left(\mathrm{PO}_{4}\right)_{5}\right] \mathrm{OH} \rightarrow \\
\beta-T C P & \text { apatitic TCP } \\
\text { [Sintering }] \rightarrow & 3 \mathrm{Ca}_{3}\left(\mathrm{PO}_{4}\right)_{2} \\
& \beta-T C P
\end{array}
$$

The slight increase of the $\mathrm{OH}^{-}$group (Figure 3a), between 3,550 and 3,600 $\mathrm{cm}^{-1}$ (Gibson et al., 2000; Anwer et al., 2016), could be the transformation of the $\beta$-TCP into apatitic TCP increasing the peak already existing with the $20 \%$ of HA of the original BCP sample. The clear new peak toward $875 \mathrm{~cm}^{-1}$
(Figure 3b) corresponds to the apparition of the $\mathrm{HPO}_{4}{ }^{2-}$ groups as described in the literature (Yubao et al., 1994; Anwer et al., 2016). At the same time, an evolution of the FTIR spectrum is noted between 500 and $600 \mathrm{~cm}^{-1}$ (Figure 3c), which correspond to $\mathrm{HPO}_{4}{ }^{2-}$ and $\mathrm{PO}_{4}{ }^{3-}$ absorption bands in apatitic chemical environments (Rey et al., 1995; Vandecandelaere et al., 2012). This sensitive method seems to clearly identify the needle-like surface layer as apatitic TCP composition. The other hypothesis, but less probable, should be the dissolution and reprecipitation of the less-soluble phase, the HA after reaction in water. In this case, as described in Eq. 2, the reaction should lead to the formation of a new calcium compound. However, no other FTIR peak apparition could prove the formation of a new compound.

$$
\mathrm{Ca}_{10}\left(\mathrm{PO}_{4}\right)_{6}(\mathrm{OH})_{2}+\mathrm{H}_{2} \mathrm{O} \rightarrow
$$

$H A$

$$
\begin{aligned}
& \mathrm{Ca}_{10-\mathrm{x}}\left[\left(\mathrm{HPO}_{4}\right)_{\mathrm{x}}\left(\mathrm{PO}_{4}\right)_{6-\mathrm{x}}\right] \mathrm{OH}_{2-\mathrm{x}}+\mathrm{xCa}^{2+} \\
& \text { apatitic CDA Ca compound }
\end{aligned}
$$

Moreover, this second hypothesis does not seem coherent with the previous results on XRD analyses (Figure 2). Indeed, the decrease of the rhombohedral phase $(\beta$-TCP) for more of a hexagonal one (apatitic form) confirms the high probability of apatitic TCP layer formation.

In order to establish the crystallographic structure of needles, an electron diffraction study (SAED) was performed on several needles. Needle-like crystals were orientated with double-tilt 

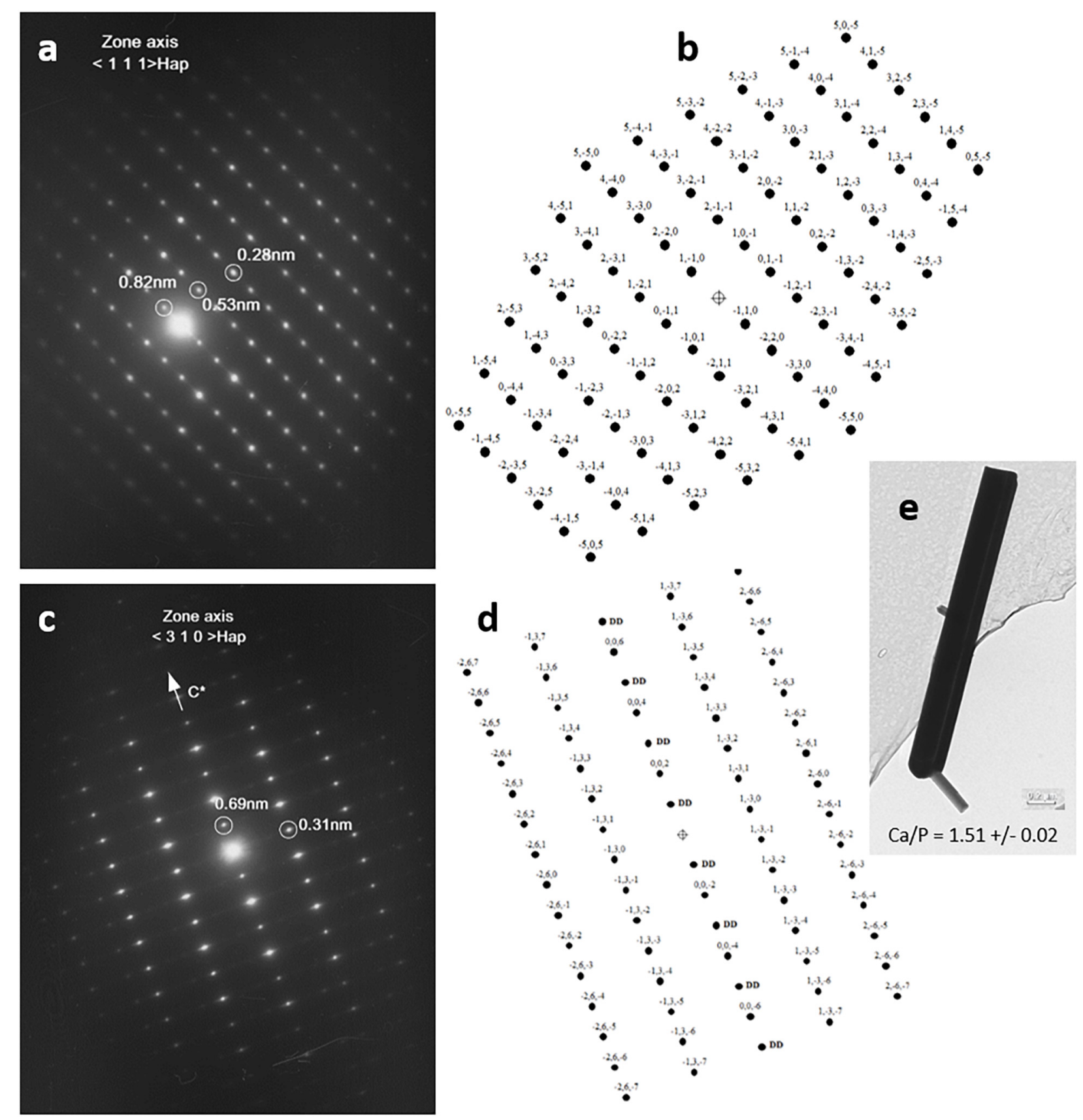

FIGURE 4 | Electron diffraction patterns of needles by transmission electron microscopy (TEM) analysis (a,c) and schematic representations of reciprocal lattice of apatitic crystals according to both crystallographic orientations, $\langle 111\rangle$ and $\langle 310\rangle$ (in $\mathbf{b}, \mathbf{d}$, respectively), and bright-field picture with the atomic Ca/P ratio determined from energy-dispersive $x$-ray spectroscopy (EDX) quantification (e).

holder in the TEM to obtain different dense planes. All needles exhibit well-crystallized ED patterns. All ED patterns were indexed according to a crystalline structure corresponding to an apatitic crystallographic cell, and none of the needles observed exhibited an ED pattern corresponding to the rhombohedral cell of $\beta$-TCP. This indicates that all observed needles have a crystallographic structure corresponding to an apatitic-like structure. Two examples are shown in Figure 4. The first one
(Figure 4a) shows one ED pattern of a needle with different interplanar distances of $0.82,0.53$, and $0.28 \mathrm{~nm}$ and angles between these plane families of $71^{\circ}$ and $90^{\circ}$, respectively with the first one, that can correspond to those of the reciprocal plane of apatitic structure with a zone axis of the electron beam orientated along the $<111>$ crystallographic axis of the apatitic cell. The schematic representation of the $2 \mathrm{D}$ reciprocal lattice corresponding to the $<111>$ zone axis of apatitic 
cell (Figure 4b) is in accordance with the ED pattern presented and gives a possible indexation of ( $\mathrm{h} \mathrm{k} \mathrm{l}$ ) planes at the origin of diffraction spots. The second one (Figure 4c) shows an ED pattern of needles with interplanar distances of 0.69 and $0.31 \mathrm{~nm}$, with an angle of $90^{\circ}$ between these two plane families that can correspond to those of the reciprocal plane of apatitic structure with a zone axis of the electron beam orientated along the $<310>$ crystallographic axis of the apatitic cell. The schematic representation of the $2 \mathrm{D}$ reciprocal lattice corresponding to the $<310>$ zone axis of apatitic cell (Figure 4d) is in accordance with the ED pattern presented and gives a possible indexation of ( $\mathrm{h} \mathrm{k} \mathrm{l}$ ) planes at the origin of diffraction spots. It should be noticed that owing to the symmetry of the crystalline cell of apatite, the diffraction spots corresponding to the $\left(\begin{array}{lll}0 & 0 & 1\end{array}\right)$ planes with 1 odd are forbidden in the reciprocal space, but spots corresponding to these indexations ( $\left.\begin{array}{lll}0 & 0 & 1\end{array}\right)$ with 1 odd are reignited by double diffraction phenomena for this zone axis orientation (DD in Figure 4d). The arrow in Figure $4 \mathbf{c}$ indicates the direction of the reciprocal crystallographic axis $\mathrm{C}^{*}$ of the apatitic structure (hexagonal axis, $c=6.9 \AA$, which coincides with the axis of needles). Figure $4 \mathbf{e}$ shows an example of a needle. Quantitative EDX microanalyses were performed on more than 10 different needles, and the mean value of the $\mathrm{Ca} / \mathrm{P}$ atomic ratio of needles determined to be 1.51 is in agreement with the chemical composition of the apatitic TCP and not with those of HA (1.67).

Rohanizadeh et al. (1998) have already shown the apatite precipitation apparition on BCP after incubation in various solutions. In a study (Tamimi et al., 2012) concerning the autoclaving of brushite into monetite-modified tomography of samples with the increase of the SSA, porosity, and interconnected macroporosity, the differences in biological properties (higher in vitro and in vivo bone regeneration properties of monetite than brushite samples) seemed to be due to the changes in the material dissolution and morphology. Other studies with TEM analyses of in vivo BCP implantation showed the precipitation of a clearly identified apatitic microcrystal around ceramic crystal in bone site and distributed without particular orientation in muscle sites (Rohanizadeh et al., 1999). Moreover, the authors observed that epitaxic growth of apatitic crystals seems more favorable from HA than $\beta$-TCP.

The combination of different characterization methods used in this study allowed for proving that the needle-like layer formation is composed of apatitic TCP chemical composition. This study demonstrates the capacity of $\mathrm{MBCP}^{\circledR}+$ granules to generate a bioactive apatitic layer, which explains the excellent

\section{REFERENCES}

Afnor (2019). NF ISO 13779, Implants for Surgery - Hydroxyapatite - Part 3: Chemical Analysis and Characterization of Crystallinity Ratio and Phase Purity. Geneva: International Organization for Standardization.

Anwer, A., Kazmi, M., Khan, Z. A., Shahzad, K., and Hussain, S. (2016). Synthesis and characterization of calcium deficient. J. Fac. Eng. Technol. 23, 101-109.

Bohne, W., Pouezat, J. A., Peru, L., and Daculsi, G. (1993). Heating of calcium phosphate crystals: morphological consequences and biological implications. Cell. Mater. 3:5. results in bone regeneration and the first choice for association in bone tissue engineering (stem cells, growth factors, and peptide). The present study shows that it is easy to control the growth of this apatitic surface layer. Further development of new bioactive medical devices are currently under progress to improve the handling properties of a bone grafts with no adverse effect on stability.

\section{DATA AVAILABILITY STATEMENT}

All datasets generated for this study are included in the article/Supplementary Material.

\section{AUTHOR CONTRIBUTIONS}

All authors listed have made a substantial, direct and intellectual contribution to the work, and approved it for publication.

\section{FUNDING}

The authors thank ORTHOUNION project from the European Union's Horizon 2020 Research and Innovation Program under Grant Agreement No. 733288 for the financial support.

\section{ACKNOWLEDGMENTS}

The authors thank Prof. C. Rey for his fruitful discussion concerning the FTIR results, F-X Lefevre from CEISAM UMR CNRS 6230, Nantes University for his technical help for atomic absorption analyses, and "Département Systèmes Energétiques et Environnement de l'École des Mines de Nantes” (IMT, Atlantique - Bretagne - Pays de la Loire) for SSA analyses. The authors also thank Nicola Piveteau for her linguistic revision of the manuscript.

\section{SUPPLEMENTARY MATERIAL}

The Supplementary Material for this article can be found online at: https://www.frontiersin.org/articles/10.3389/fbioe. 2019.00462/full\#supplementary-material

DATA S1 | Denominations of study samples.

Bohner, M. (2010). Design of ceramic-based cements and putties for bone graft substitution. Eur. Cell. Mater. 20, 1-12. doi: 10.22203/ecm.v020a01

Bohner, M., and Miron, R. J. (2019). A proposed mechanism for material-induced heterotopic ossification. Mater. Today 22, 132-141. doi: 10.1016/j.mattod.2018. 10.036

Bourges, X., Schmitt, M., Amouriq, Y., Daculsi, G., Legeay, G., and Weiss, P. (2001). Interaction between hydroxypropyl methylcellulose and biphasic calcium phosphate after steam sterilisation: capillary gas chromatography studies. J. Biomater. Sci. Polym. Ed. 12, 573-579. doi: 10.1163/15685620131688 3412 
Brennan, M. Á, Renaud, A., Amiaud, J., Rojewski, M. T., Schrezenmeier, H., Heymann, D., et al. (2014). Pre-clinical studies of bone regeneration with human bone marrow stromal cells and biphasic calcium phosphate. Stem Cell Res. Ther. 5:114. doi: 10.1186/scrt504

Champion, E. (2013). Sintering of calcium phosphate bioceramics. Acta Biomater. 9, 5855-5875. doi: 10.1016/j.actbio.2012.11.029

Cordonnier, T., Layrolle, P., Gaillard, J., Langonné, A., Sensebe, L., Rosset, P., et al. (2010). 3D environment on human mesenchymal stem cells differentiation for bone tissue engineering. J. Mater. Sci. Mater. Med. 21, 981-987. doi: 10.1007/ s10856-009-3916-9

Daculsi, G. (2015). Smart scaffolds: the future of bioceramic. J. Mater. Sci. Mater. Med. 26:154. doi: 10.1007/s10856-015-5482-7

Daculsi, G., and Layrolle, P. (2004). Osteoinductive properties of micro macroporous biphasic calcium phosphate bioceramics. Key Eng. Mater. 254256, 1005-1008. doi: 10.4028/www.scientific.net/kem.254-256.1005

Daculsi, G., LeGeros, R. Z., Heughebaert, M., and Barbieux, I. (1990). Formation of carbonate-apatite crystals after implantation of calcium phosphate ceramics. Calcif. Tissue Int. 46, 20-27. doi: 10.1007/bf02555820

Daculsi, G., Legeros, R. Z., Legeros, J. P., and Mitre, D. (2005). Lattice defects in calcium phosphate ceramics: high resolution TEM ultrastructural study. J. Appl. Biomater. 2, 147-152. doi: 10.1002/jab.770020302

Daculsi, P. G., Corre, P., Malard, O., Legeros, R., and Goyenvalle, E. (2006). Performance for bone ingrowth of biphasic calcium phosphate ceramic versus bovine bone substitute. Key Eng. Mater. 18, 1379-1382. doi: 10.4028/www. scientific.net/kem.309-311.1379

Davison, N., Yuan, H., de Bruijn, J. D., and Barrere-de Groot, F. (2012). In vivo performance of microstructured calcium phosphate formulated in novel waterfree carriers. Acta Biomater. 8, 2759-2769. doi: 10.1016/j.actbio.2012.04.007

De Groot-Barrere, F., Van Miegem, V., Yuan, H., and Debruijn, J. (2015). Method for producing an osteoinductive calcium phosphate and products thus obtained. Patent No. P100479.

Dorozhkin S. V. (2010). Bioceramics of calcium orthophosphates. Biomaterials 31, 1465-1485. doi: 10.1016/j.biomaterials.2009.11.050

Duan, R., Barbieri, D., Luo, X., Weng, J., Bao, C., De Bruijn, J. D., et al. (2018). Variation of the bone forming ability with the physicochemical properties of calcium phosphate bone substitutes. Biomater. Sci. 6, 136-145. doi: 10.1039/ c7bm00717e

Duan, R., van Dijk, L. A., Barbieri, D., de Groot, F., Yuan, H., and de Bruijn, J. D. (2019). Accelerated bone formation by biphasic calcium phosphate with a novel sub-micron surface topography. Eur. Cell. Mater. 37, 60-73. doi: 10.22203/eCM. v037a05

Eliaz, N., and Metoki, N. (2017). Calcium phosphate bioceramics: a review of their history, structure, properties, coating technologies and biomedical applications. Materials (Basel) 10:334. doi: 10.3390/ma10040334

Gauthier, O., Bouler, J. M., Aguado, E., Legeros, R. Z., Pilet, P., and Daculsi, G. (1999). Elaboration conditions influence physicochemical properties and in vivo bioactivity of macroporous biphasic calcium phosphate ceramics. J. Mater. Sci. Mater. Med. 10, 199-204.

Giannoudis, P. V., Dinopoulos, H., and Tsiridis, E. (2005). Bone substitutes: an update. Injury 36(Suppl. 3), S20-S27. doi: 10.1016/j.injury.2005.07.029

Gibson, I. R., Rehman, I., Best, S. M., Bonfield, W., Materials, B., and Mary, Q. (2000). Characterization of the transformation from calcium-de ${ }^{\circledR}$ cient apatite to b-tricalcium phosphate. 1, 533-539.

Gjerde, C., Mustafa, K., Hellem, S., Rojewski, M., Gjengedal, H., Yassin, M. A., et al. (2018). Cell therapy induced regeneration of severely atrophied mandibular bone in a clinical trial. Stem Cell Res. Ther. 9:213. doi: 10.1186/s13287-0180951-9

Gómez-Barrena, E., Rosset, P., Gebhard, F., Hernigou, P., Baldini, N., Rouard, H., et al. (2019). Feasibility and safety of treating non-unions in tibia, femur and humerus with autologous, expanded, bone marrow-derived mesenchymal stromal cells associated with biphasic calcium phosphate biomaterials in a multicentric, non-comparative trial. Biomaterials 196, 100-108. doi: 10.1016/ j.biomaterials.2018.03.033

Habibovic, P., Sees, T. M., Van Den Doel, M. A., Van Blitterswijk, C. A., and De Groot, K. (2006a). Osteoinduction by biomaterials- physicochemical and structural influences. J. Biomed. Mater. Res. A 77, 747-762. doi: 10.1002/jbm.a. 30712
Habibovic, P., Yuan, H., van den Doel, M., Sees, T. M., van Blitterswijk, C. A., and de Groot, K. (2006b). Relevance of osteoinductive biomaterials in critical-sized orthotopic defect. J. Orthop. Res. 24, 867-876. doi: 10.1002/jor. 20115

Habraken, W., Habibovic, P., Epple, M., and Bohner, M. (2016). Calcium phosphates in biomedical applications: materials for the future? Mater. Today 19, 69-87. doi: 10.1016/j.mattod.2015.10.008

Heary, R. F., Schlenk, R. P., Sacchieri, T. A., Barone, D., and Brotea, C. (2002). Persistent iliac crest donor site pain: independent outcome assessment. Neurosurgery 50, 510-517. doi: 10.1227/00006123-20020300000015

Kokubo, T., and Takadama, H. (2006). How useful is SBF in predicting in vivo bone bioactivity? Biomaterials 27, 2907-2915. doi: 10.1016/j.biomaterials.2006. 01.017

LeGeros, R. Z. (2008). Calcium phosphate-based osteoinductive materials. Chem. Rev. 108, 4742-4753. doi: 10.1021/cr800427g

Lin, S. J, Legeros, R. Z., Rohanizadeh, R., Mijares, D. Q, and Legeros, J. P. (2003). Biphasic calcium phosphate (BCP) bioceramics: preparation and properties. Key Eng. Mater. 240-242, 473-476. doi: 10.4028/www.scientific.net/kem.240242.473

Miramond, T., Corre, P., Aguado, E., Borget, P., Moreau, F., and Daculsi, G. (2014a). Osteoinduction and osteopromotion of smart biphasic calcium phosphate scaffolds MBCP (R): in vivo proof of concept. J. Tissue Eng. Regen. Med. 8, 153-153.

Miramond, T., Rouillon, T., and Daculsi, G. (2014b). Biphasic calcium phosphate: preferential ionic substitutions and crystallographic relationships at grain boundaries. Key Eng. Mater. 631, 73-77. doi: 10.4028/www.scientific.net/kem. 631.73

Mortier, A., Lemaitre, J., Rodrique, L., and Rouxhet, P. G. (1989a). Synthesis and thermal behavior of well-crystallized calcium-deficient phosphate apatite. J. Solid State Chem. 78, 215-219. doi: 10.1016/0022-4596(89) 90099-6

Mortier, A., Lemaitre, J., and Rouxhet, P. G. (1989b). Temperature-programmed characterization of synthetic calcium-deficient phosphate apatites. Thermochim. Acta 143, 265-282. doi: 10.1016/0040-6031(89)85065-8

Rey, C., Miquel, J. L., Facchini, L., Legrand, A. P., and Glimcher, M. J. (1995). Hydroxyl groups in bone mineral. Bone 16, 583-586. doi: 10.1016/87563282(95)00101-I

Rohanizadeh, R., Padrines, M., Bouler, J. M., Couchourel, D., Fortun, Y., and Daculsi, G. (1998). Apatite precipitation after incubation of biphasic calciumphosphate ceramic in various solutions: influence of seed species and proteins. J. Biomed. Mater. Res. 42, 530-539. doi: 10.1002/(SICI)1097-4636(19981215)42: 4<530::AID-JBM8<3.0.CO;2-6

Rohanizadeh, R., Trécant-Viana, M., and Daculsi, G. (1999). Ultrastructural study of apatite precipitation in implanted calcium phosphate ceramic: influence of the implantation site. Calcif. Tissue Int. 64, 430-436. doi: 10.1007/PL0000 5825

Schmitt, M., Weiss, P., Bourges, X., Amador del Valle, G., and Daculsi, G. (2002). Crystallization at the polymer/calcium-phosphate interface in a sterilized injectable bone substitute IBS. Biomaterials 23, 2789-2794. doi: 10.1016/s01429612(02)00015-7

Silber, J. S., Anderson, D. G., Daffner, S. D., Brislin, B. T., Leland, J. M., Hilibrand, A. S., et al. (2003). Donor site morbidity after anterior iliac crest bone harvest for single-level anterior cervical discectomy and fusion. Spine (Phila Pa 1976) 28, 134-139. doi: 10.1097/00007632-20030115000008

Smucker, J. D., Bobst, J. A., Petersen, E. B., Nepola, J. V., and Fredericks, D. C. (2008). B2A peptide on ceramic granules enhance posterolateral spinal fusion in rabbits compared with autograft. Spine (Phila $\mathrm{Pa}$ 1976) 33, 1324-1329. doi: 10.1097/BRS.0b013e3181732a74

Tamimi, F., Le Nihouannen, D., Eimar, H., Sheikh, Z., Komarova, S., and Barralet, J. (2012). The effect of autoclaving on the physical and biological properties of dicalcium phosphate dihydrate bioceramics: Brushite vs. monetite. Acta Biomater. 8, 3161-3169. doi: 10.1016/j.actbio.2012.04.025

Vandecandelaere, N., Rey, C., and Drouet, C. (2012). Biomimetic apatite-based biomaterials: on the critical impact of synthesis and post-synthesis parameters. J. Mater. Sci. Mater. Med. 23, 2593-2606. doi: 10.1007/s10856-012-4719-y 
Wagner, Q., Benkirane-Jessel, N., Fernandez de Grado, G., Musset, A.M., Bornert, F., Keller, L., et al. (2018). Bone substitutes: a review of their characteristics, clinical use, and perspectives for large bone defects management. J. Tissue Eng. 9:204173141877681. doi: 10.1177/204173141877 6819

Yubao, L., De Groot, K., De Wijn, J., Klein, C. P. A. T., and Meer, S. V. D. (1994). Morphology and composition of nanograde calcium phosphate needle-like crystals formed by simple hydrothermal treatment. J. Mater. Sci. Mater. Med. 5, 326-331. doi: 10.1007/BF0005 8956

Zhang, K., Wang, S., Zhou, C., Cheng, L., Gao, X., and Xie, X. (2018). Advanced smart biomaterials and constructs for hard tissue engineering and regeneration. Bone Res. 6:31. doi: 10.1038/s41413-0180032-9
Conflict of Interest: CD'A and PB are employees of the Biomatlante - Advanced Medical Solutions Group plc Company.

The remaining authors declare that the research was conducted in the absence of any commercial or financial relationships that could be construed as a potential conflict of interest.

Copyright (c) 2020 d'Arros, Rouillon, Veziers, Malard, Borget and Daculsi. This is an open-access article distributed under the terms of the Creative Commons Attribution License (CC BY). The use, distribution or reproduction in other forums is permitted, provided the original author(s) and the copyright owner(s) are credited and that the original publication in this journal is cited, in accordance with accepted academic practice. No use, distribution or reproduction is permitted which does not comply with these terms. 